\title{
Informed shared decision making: An exploratory study in pharmacy
}

\author{
Rosemin KASSAM, Carlyn VOLUME-SMITH, Simon P. ALBON
}

Received (first version): 17-Nov-2007

Accepted: 17-Mar-2008

\begin{abstract}
${ }^{*}$
Introduction: A study was undertaken to examine the feasibility of using the physician-based Informed Shared Decision Making (ISDM) framework for teaching pharmacy students competencies to effectively develop therapeutic relationships with patients.

Objectives: To: (1) assess the relevance and importance of the physician-developed ISDM competencies for pharmacy practice, (2) determine which competencies would be easiest and hardest to practice, (3) identify barriers to implementing ISDM in pharmacy practice, and (4) identify typical situations in which ISDM is or could be practiced. Methods: Twenty pharmacists representing 4 different practices were interviewed using a standardized interview protocol.

Results: Pharmacists acknowledged that majority of the physician-based competencies were relevant to pharmacy practice; although not all competencies were considered to be most important. Competency \#1 (Develop a partnership with the patient) was found to be the most relevant, the most important and the easiest to practice of all the competencies. While no one competency was identified as being hard to practice, there were several barriers identified to practicing ISDM. Finally, pharmacists expressed that patients with chronic conditions would be the most ideal for engaging in ISDM. Conclusion: While pharmacists believed that the ISDM model could provide a framework for pharmacists to develop therapeutic relationships with their patients, the group also identified obstacles to engaging successfully in this relationship.
\end{abstract}

Keywords: Pharmacist. Decision Making. Patient Participation. Cooperative Behavior.

\footnotetext{
*Rosemin KASSAM. BSc. Pharm., PharmD. Associate Professor and Director of the Structured Practice Education Programs. Faculty of Pharmaceutical Sciences, University of British Columbia. Vancouver, BC (Canada). Carlyn VOLUME-SMITH. BSc. Pharm., MSc., PhD. Senior Manager, Scientific and Research Services. Alberta Blue Cross. Edmonton, AL (Canada).

Simon P. ALBON. MSc. Senior Instructor. Faculty of Pharmaceutical Sciences, University of British Columbia. Vancouver, BC (Canada).
}

\author{
TOMA DE DECISIONES INFORMADAS \\ COMPARTIDAS: ESTUDIO \\ EXPLORATORIO EN FARMACIA
}

\section{RESUMEN}

Introducción: Se realizó un estudio para examinar la factibilidad de usar un entorno de Toma de Decisiones Informadas Compartidas (TDIC) de los médicos para enseñar a los estudiantes de farmacia competencias para desarrollar relaciones con los pacientes de modo efectivo.

Objetivo: (1) evaluar la relevancia y la importancia de la TDIC de los médicos para el ejercicio de la farmacia, (2) determinar que competencias serían las más fáciles y las más difíciles para la farmacia, (3) identificar barreras para la implantación de la TDIC en el ejercicio de la farmacia, y (4) identificar situaciones típicas en las que la TDIC se ejerce o podría.

Métodos: Se entrevistó a 20 farmacéuticos de diferentes ejercicios utilizando un protocolo estandarizado.

Resultados: Los farmacéuticos reconocieron que la mayoría de las competencias de los médicos eran relevantes al ejercicio de la farmacia; aunque no todas las competencias fueron consideradas como las más importantes. La competencia \#1 (Desarrollar una colaboración con el paciente) fue calificada como las más relevante, la más importante y la más fácil para el ejercicio de todas las competencias. Mientras que ninguna competencia fue considerada como difícil de ejercer, se identificaron varias barreras para el ejercicio de la TDIC. Finalmente, los farmacéuticos expresaron que los pacientes con enfermedades crónicas serían los ideales para incorporar en la TDIC.

Conclusión: Aunque los farmacéuticos creyeron que el modelo TDIC podría proporcionar un marco para desarrollar relaciones terapéuticas con sus pacientes, el grupo también identificó obstáculos para iniciar con éxito esta relación.

Palabras clave: Farmacéutico. Toma de decisiones. Participación del paciente. Comportamiento cooperativo.

\section{INTRODUCTION}

The health professional literature suggests that involving patients in their health care tends to 
achieve better adherence to treatment plans and health outcomes. ${ }^{1-26}$ As a result, over the past decade, social, professional and economic trends in society have recognized the need for greater involvement of patients in health care decisionmaking. ${ }^{1,27-31}$ In pharmacy, across Canada, professional organizations have also adopted patient-centred care as the new professional mandate. ${ }^{28,29}$ This shift is manifest in the "pharmaceutical care" practice philosophy, defined as that "component of pharmacy practice which entails the direct interaction of the pharmacist with the patient for the purpose of caring for the patient's drug-related needs". ${ }^{3}$ Additionally, in 1994, the Association of Faculties of Pharmacy of Canada and the Canadian Council for Accreditation of Pharmacy Programs, the national organizations responsible for setting educational guidelines and accreditation standards for Canadian pharmacy schools, adopted pharmaceutical care as a primary practice responsibility of pharmacists. ${ }^{3,33}$ In response to this trend, many schools of pharmacy have made great strides in ensuring graduates have the technical skills and the theoretical knowledge to engage in pharmaceutical care; however, schools have not been as successful in fostering the interpersonal communication skills that can make the difference between a positive and a negative patient-pharmacist relationaship. ${ }^{34}$ This is despite there being a general acceptance among pharmacy practitioners that the development of such a relationship requires specific interpersonal skills and is difficult to do.

The fundamental patient-pharmacist relationship in pharmaceutical care has been termed the therapeutic relationship (please note: the terms therapeutic relationship and relationship will be used synonymously in this paper). Within such a relationship, the pharmacist and patient form a partnership for the purpose of achieving desired drug therapy goals. This relationship emphasizes the patients' involvement in the management of their health and on decisions that are both shared by the pharmacist and the patient, and informed by best evidence. As illustrated in Figure 1, the therapeutic relationship consists of 2 crucial elements, a covenant and open dialogue. ${ }^{2}$ The covenant is defined as the "bond between the pharmacist and patient ... that cements the therapeutic relationship", and is seen as "a mutually beneficial exchange in which the patient grants the authority to the provider and the provider gives competence and commitment to the patient". 2,4 Inherent in the covenant is a consensus on the specific goals of the partnership and the roles and responsibilities of each party in achieving these goals. The covenant, however, is usually not formed immediately after a pharmacist and patient meet, but instead occurs gradually through open dialogue, the other crucial element of the therapeutic relationship. Initially, the dialogue is important in establishing the alliance between the pharmacist and patient and, later, in maintaining and nurturing a collaborative relationship for as long as pharmaceutical care is provided. It is through this dialogue that the pharmacist and the patient define their roles and responsibilities, set specific goals for the partnership, and establish the framework for decision-making by identifying the patient's health needs, preferences, and wishes. It is also during this dialogue that the pharmacist must apprise the patient of the various risks and benefits of drug therapy options and of instances where one option may be more beneficial based on the pharmacist's professional judgment. ${ }^{2,30}$

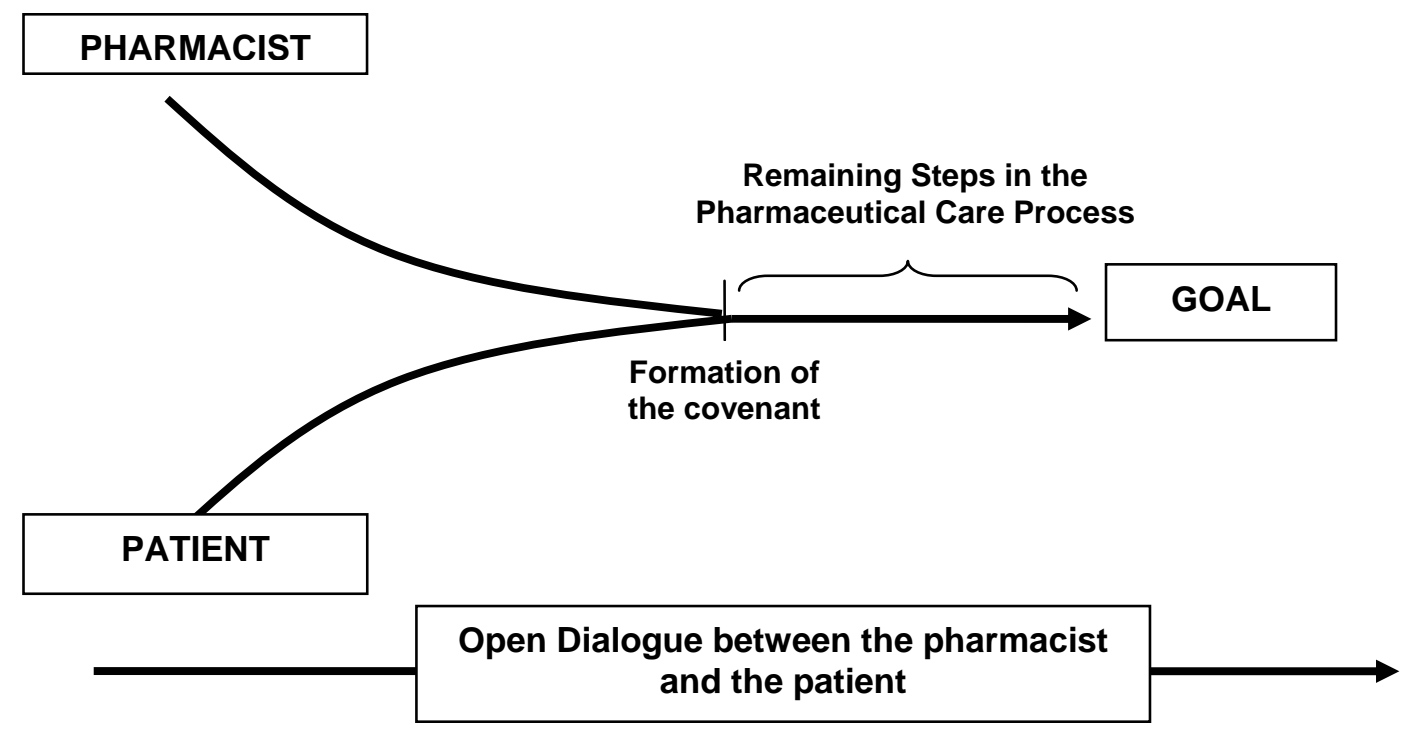

Figure 1. The process of developing and sustaining a therapeutic relationship. 
While the covenantal component of the therapeutic relationship has been well defined in the literature, the mechanism of how to engage in the open dialogue - the crux of what makes this relationship possible, has not been adequately articulated. ${ }^{2,3} \mathrm{~A}$ literature search using Medline, ERIC, and International Pharmaceutical Abstracts databases affirmed the importance of the therapeutic relationship, defined important components of the relationship, identified pharmacists' current skill deficiencies related to developing such relationships, and provided specific strategies to improve patient-pharmacist communication and pharmacy-related activities such as counseling., ${ }^{2,3,5-}$ 0,30 However, a minimum set of criteria that pharmacists can use to evaluate themselves against, to determine whether or not their patientencounters reflected a therapeutic relationship, was not evident. In addition, no example of a wellarticulated teaching and learning framework for developing a therapeutic relationship was found. Thus, development of an effective therapeutic relationship appears to be another example of the "theory-practice" gap in pharmacy practice, where although there is a strong theoretical rationale for this relationship to exist there is very little established research to help guide pharmacists and pharmacy educators on how to put it into practice.

To assist with the development of teaching materials to enhance pharmacy students' abilities to engage in therapeutic relationships, the Faculty of Pharmaceutical Sciences at the University of British Columbia (UBC) considered adopting an interpersonal communication skills training module, informed shared decision-making (ISDM), designed by the Division of Health Communications - College of Health Disciplines for UBC medical students. While the benefits of the ISDM model to patients' health outcomes had not yet been quantified, it presented many desirable characteristics important for pharmacy (Refer to Table 1). The ISDM model shared similarities with the therapeutic relationship model in that it described decisions that are shared by the doctor and the patient, are informed by best evidence (not only about risks and benefits but also patient specific characteristics and values), and occur in a partnership that rests on explicit acknowledged rights, duties and expectations. ${ }^{11}$ Weston has described ISDM as "a meeting between experts", in which the physician is the expert on the disease itself and the patient is the expert on their own experience of the disease. ${ }^{35}$ Of future importance, the UBC Faculty of Pharmaceutical Sciences believed that adopting the ISDM model would create a common language and approach across health disciplines for involving patients in their care, as well as facilitate interprofessional collaborative practice opportunities at UBC. The ISDM model consists of eight competencies, which serve as a framework for teaching, learning and practicing ISDM. Additionally, an ISDM in-class training module, designed for medical students prior to them applying ISDM during their experiential medical training, was readily available for adaptation for training pharmacy students and preceptors. The module involved students observing ISDM encounters on videos using physician-patient encounters, followed by roleplaying with trained standardized patients.

Consequently, as a first step to introducing the ISDM model into the UBC pharmacy curriculum, a research grant was secured to undertake an exploratory study to gain insight into pharmacists' perspectives of the ISDM model and potential benefits of this model to pharmacy education and practice. The objectives of the study were to: (1) assess the relevance and the importance of the physician-developed ISDM competencies for pharmacy practice from the perspective of pharmacists, (2) determine which physician-specific competencies would be the easiest and hardest to practice in pharmacy, (3) identify barriers to implementing ISDM in pharmacy practice, and (4) identify typical situations in which ISDM is or could be practiced. The intent of this paper is to share these findings.

Table 1. Informed Shared Decision Making (ISDM) competencies for physicians.

The physician is able to:

1. Develop a partnership with the patient/client

2. Establish or review the patient's/client's preferences for information (eg. Amount, format)

3. Establish or review the patient's/client's preferences for role in decision making (eg. risk taking; degree of involvement of self and others), and the existence/nature/degree of decisional conflict. [Decisional conflict is a state of uncertainty about the course of action to take]

4. Ascertain and respond to patient's/client's ideas, concerns and expectations (eg. about disease, management options).

5. Identify choices (including ideas and information patient/client may have) and evaluate the research evidence in relation to the individual patient/client.

6. Present (or direct to) evidence taking into account \#2 and \#3, framing effects, etc. and help patient/client to reflect upon and assess the impact of alternative decisions vis a vis their values and lifestyle. [Framing effects are said to occur when the presentation of the same information in different formats changes the decisions that people make].

7. Make or negotiate a decision in partnership and resolve conflict.

8. Agree upon an action plan and complete arrangements for follow-up.

\section{METHODS}

\section{Design}

The exploratory study was carried out between June and August 2001. A student researcher was recruited to conduct semi-structured face-to-face interviews with practicing pharmacists. Ethics approval for the project was obtained from UBC's Behavioural Research Ethics Board.

\section{Sampling}

The Director of the pharmacy experiential program generated a list of pharmacists who had a history of serving as preceptors with UBC. The pharmacists represented four categories of practitioners: (1) community pharmacists with a Bachelaureate of 
Science in Pharmacy (B.Sc. Pharm) degree involved primarily in dispensing of medications and providing basic counseling (the Community Dispensing category), (2) community pharmacists with a B.Sc. Pharm degree participating in disease management programs offered through their pharmacy (the Community Disease Management category), (3) hospital pharmacists with a B.Sc. Pharm degree (the Hospital B.Sc. Pharm category) and (4) hospital pharmacists with both B.Sc. Pharm and post-graduate Doctor of Pharmacy (PharmD) degrees (the Hospital PharmD category). Potential participants from each category of practitioner were selected at random by the student researcher and invited to participate in the study. The first five pharmacists that agreed to participate and sign a consent form were recruited, resulting in a total of 20 participants. As part of the recruitment process, the pharmacists received a recruitment letter, the list of ISDM competencies for physicians, a draft of the questions to be asked during the interview and the study consent form. Provisions were made to recruit and interview additional pharmacists from each category should new themes emerge during the interview process suggesting data saturation had not occurred. ${ }^{36}$

\section{Data collection}

Using a semi-structured interview process, the student researcher conducted one-hour face-to-face interviews with each pharmacist to explore questions for each of the eight physician-based competencies. The structured component of the interview consisted of nine questions related to the physician-based competencies: (1) Which competencies are relevant to pharmacy?, (2) Which competencies are the most important for pharmacy?, (3) Which competencies are easiest to perform in pharmacy practice?, (4) Which competencies are most difficult to achieve in pharmacy practice?, (5) What are the barriers to putting ISDM into practice?, (6) How did you learn to practice these competencies?, (7) What two or three typical pharmacist-patient situations could ISDM be practiced in?, (8) Do you think ISDM competencies should be incorporated into the pharmaceutical care model of practice?, and, (9) What do you do when the patient still wants to go against what you have recommended? For questions \#1 - 4, the pharmacists were first asked to review the list of eight competencies one at a time, and to provide a "yes or no" response to each question before providing their perspectives. Following this, pharmacists were asked for their comments on the remaining questions. In addition, demographic, practice and education information were collected from each study pharmacist. Prior to the interview process, the study pharmacists and Faculty members from the division of pharmacy practice and clinical pharmacy were asked to review the interview questions for face-validity. Signed consent forms were collected immediately prior to the interviews and all interview data were collected with the assurance of anonymity and confidentiality.

\section{Data analysis}

The interview data was summarized using a blend of quantitative and qualitative methods. ${ }^{36}$ Interviews were audiotaped and transcribed by the student researcher within 24 hours of their completion. Each pharmacist was then asked to review the transcripts and amend or offer additional suggestions. Responses were summarized into tables, grouped according to the practice categories, and tabulated. Transcripts were also analyzed to identify common themes and produce an overall pharmacist evaluation of the physician-based ISDM competencies. The student researcher and project leader reviewed the transcripts line-by-line and coded the text according to themes. These themes were then grouped into larger categories. In addition, simple frequency tallies were used to summarize the "yes" and "no" responses related to questions \#1 - 4 .

\section{RESULTS}

Of the 20 pharmacists that participated, $55 \%$ were male. $35 \%$ of the pharmacists were between the ages of 30-39, 25\% were between 20-29 and 40-49 respectively, and $15 \%$ were over the age of 50 . The mean time since graduating with a B.Sc. Pharm degree was $14.7(\mathrm{SD}=9.9)$ years, and $4.2(S D=2.2)$ years since graduating with a PharmD degree. Two pharmacists, one from the Community Dispensing category and one from the Hospital B.Sc. Pharm category, had completed a Master's degree in pharmaceutical sciences. All hospital pharmacists had completed a residency program.

Table 2 summaries the participating pharmacists' perspectives regarding the relevance and importance of the physician ISDM competencies to pharmacy practice. Based on the totals across all categories, at least $70 \%$ of pharmacists agreed that all but one of the physician-specific competencies were relevant to pharmacy practice. Competency \#3 (Establish patient's preference for role in decision making) was perceived to be the least relevant, with only $60 \%$ agreement across all categories; the largest endorsement coming from the Hospital B.Sc. Pharm category. Other interesting observations included: only 1 pharmacist from the Community Dispensing category stated that competency \#5 (Identify choices and evaluate the evidence) was relevant, only two pharmacists from the Community Disease Management category stated that competency \#3 (Establish patient's preference for role in decision making) was relevant and, only two from the Hospital B.Sc. Pharm category stated that competencies \#6 (Present evidence) and \#7 (Negotiate a decision) were relevant to pharmacy practice.

When asked to confirm which of the competencies were most important for pharmacy, $80 \%$ of all pharmacists agreed that competency \#1 (Developing a partnership with the patient) was the most important. This theme was eloquently articulated by two pharmacists from the Community Dispensing category when they stated that, "building a partnership with the patient is one of the 
pharmacist's main roles" and "it is essential to providing any kind of care to the patient". Another recurring notion during this discussion was the importance the pharmacists placed on their relationships with physicians and other health care providers, in addition to that of the patient. As one community pharmacist from the dispensing group expressed "when you're talking about informed shared decision making, you're talking about giving the patient a well-rounded view of the whole situation, so you want to have all health care professionals interacting". A similar view was shared by one of the PharmD participants, who stressed that "everyone involved in a patient's care needs to be on the same page regarding the patient's action plan" and "professional opinions need to be sorted out so that a united front is presented".

Conversely, there was not a similar unanimity amongst the pharmacists in all four groups with respect to the importance of the other competencies. For instance, only $25 \%$ tagged competency \#3 (Establish patient's preference for role in decision making) to be most important. While the Hospital B.Sc. Pharm group recognized competencies \#4 (Respond to patient's ideas, concerns and expectations), \#5 (Identify choices and evaluate evidence) and \#6 (Present evidence) to also be most important, few pharmacists amongst the Hospital PharmD group rated any of these competencies as being most important. However, despite this discrepancy, there were interesting perspectives shared by pharmacists in all four groups during these discussions. For example, pharmacists from both community pharmacy categories as well as those in the Hospital B.Sc. Pharm category, viewed themselves as information providers and felt "it was the doctor's responsibility to make decisions regarding treatments". Similarly, several pharmacists expressed reluctance to dispute a physician's therapeutic choice unless it was unsafe for the patient; voicing that it was important to not step out of their "professional realm". With respect to competency \#2 (Establish patient's preferences for information), it was interesting to note the pharmacists' reluctance to obtain patients' preferences and to relinquish their paternalistic habits. While most of the pharmacists recognized the importance of patient autonomy when the patient was sufficiently informed and that the decision was ultimately the patients to make, there were pharmacists in each group that said they would "try to convince the patient if they did not agree with their decision". Furthermore, pharmacists from each group indicated that they often decided what form and what amount of information was appropriate for their patient, based on their knowledge and past experience with that patient.

Table 2. The pharmacists' perspectives regarding the relevance and importance of the physician Informed Shared Decision Making (ISDM) competencies to pharmacy practice

\begin{tabular}{|c|c|c|c|c|c|}
\hline \multirow[b]{2}{*}{ Competency ${ }^{*}$} & \multirow[b]{2}{*}{$\begin{array}{c}\text { Totals } \\
\text { All Categories } \\
n=20\end{array}$} & \multicolumn{4}{|c|}{ Pharmacy Categories $^{\dagger}$} \\
\hline & & $\begin{array}{c}\text { Community } \\
\text { Dispensing } \\
n=5\end{array}$ & $\begin{array}{c}\text { Community } \\
\text { Disease } \\
\text { Management } \\
n=5\end{array}$ & $\begin{array}{c}\text { Hospital } \\
\text { B.Sc.Pharm } \\
\text { n=5 }\end{array}$ & $\begin{array}{l}\text { Hospital } \\
\text { PharmD } \\
n=5\end{array}$ \\
\hline & $\mathrm{R} / \mathrm{I}$ & $\mathrm{R} / \mathrm{I}$ & $\mathrm{R} / \mathrm{I}$ & $\mathrm{R} / \mathrm{I}$ & $\mathrm{R} / \mathrm{I}$ \\
\hline 1. Develop a partnership with the patient & $20(100 \%) / 16(80 \%)$ & $5 / 4$ & $5 / 5$ & $5 / 5$ & $5 / 2$ \\
\hline $\begin{array}{l}\text { 2. Establish patient's preferences for } \\
\text { information }\end{array}$ & $20(100 \%) / 10(50 \%)$ & $5 / 3$ & $5 / 2$ & $5 / 3$ & $5 / 2$ \\
\hline $\begin{array}{l}\text { 3. Establish patient's preferences for role } \\
\text { in decision making }\end{array}$ & $12(60 \%) / 5(25 \%)$ & $3 / 1$ & $2 / 0$ & $4 / 3$ & $3 / 1$ \\
\hline $\begin{array}{l}\text { 4. Respond to the patient's ideas, } \\
\text { concerns \& expectations }\end{array}$ & $18(90 \%) / 10(50 \%)$ & $5 / 2$ & $4 / 2$ & $4 / 4$ & $5 / 2$ \\
\hline $\begin{array}{l}\text { 5. Identify choices \& evaluate the } \\
\text { evidence }\end{array}$ & $14(70 \%) / 8(40 \%)$ & $1 / 1$ & $4 / 2$ & $4 / 4$ & $5 / 1$ \\
\hline 6. Present evidence & $15(75 \%) / 8(40 \%)$ & $4 / 1$ & $5 / 1$ & $2 / 4$ & $4 / 2$ \\
\hline 7. Negotiate a decision & $15(75 \%) / 8(40 \%)$ & $5 / 1$ & $3 / 2$ & $2 / 3$ & $5 / 2$ \\
\hline 8. Agree on an action plan and follow-up & $20(100 \%) / 9(45 \%)$ & $5 / 2$ & $5 / 2$ & $5 / 3$ & $5 / 2$ \\
\hline
\end{tabular}

Table 3 identifies the competencies rated as being the easiest and hardest to practice by participating pharmacists across all four categories. Overall, $75 \%$ of pharmacists across all categories identified competency \#1 (Developing a partnership with the patient) as being the easiest to practice, followed by competency \#2 (Establish patient's preferences for information) at $40 \%$. This pattern of response was observed in each of the four categories, with the exception of the hospital B.Sc. Pharm group where only one pharmacist stated competency \#2 (Establish patient's preferences for information) was easy to practice. Interestingly, no one competency emerged strongly as the most difficult competency to practice. Competency \#8 (Agree on an action plan and follow-up) was identified by $35 \%$ of all participants to be somewhat difficult to practice, followed by competency \#6 (Present evidence) at $30 \%$.

During the interviews, pharmacists identified numerous barriers to ISDM. When these barriers were grouped into categories, four key themes emerged that included: 1) barriers related to the pharmacists' work environments (Work Environment), 2) barriers related to the pharmacists (Pharmacist), 3) barriers related to patients (Patient), and, 4) barriers related to the health care system (Health System). The most common barriers related to Work Environment, consistent across all 
pharmacist categories, included "lack of time to engage in ISDM", "workload/ pharmacist shortage/ limited role of the technician/ dispensary responsibilities" and "lack of remuneration". The most common pharmacist-specific barrier expressed across all 4 categories included "lack of skills, knowledge, education related to ISDM and lack of a framework to practice patient-centered care", followed by "resistance by pharmacists to engage in ISDM". Within the patient-specific theme, the most common barriers perceived across all four pharmacist categories were "patients' indifference to health", "language/ cultural issues" and "perception of pharmacy". Finally, the most common barriers related to the Health System identified by all pharmacists included "lack of collaboration between health professionals/ ISDM not practiced universally" and "professional boundaries/ physician resistance/ no formal structure for pharmacist involvement/ lack of access to physicians". Barriers to ISDM reported by pharmacists are outlined in more detail in Table 4.

\begin{tabular}{|c|c|c|c|c|c|}
\hline \multirow[b]{2}{*}{ Competency ${ }^{*}$} & \multirow[b]{2}{*}{$\begin{array}{c}\text { Totals } \\
\text { All Categories } \\
n=20\end{array}$} & \multicolumn{4}{|c|}{ Pharmacy Categories $^{\dagger}$} \\
\hline & & $\begin{array}{c}\text { Community } \\
\text { Dispensing } \\
\mathrm{n}=5\end{array}$ & $\begin{array}{c}\text { Community } \\
\text { Disease } \\
\text { Management } \\
n=5\end{array}$ & $\begin{array}{c}\text { Hospital } \\
\text { B.Sc.Pharm } \\
n=5\end{array}$ & $\begin{array}{c}\text { Hospital } \\
\text { PharmD } \\
n=5\end{array}$ \\
\hline & $\mathrm{E} / \mathrm{H}$ & $\mathrm{E} / \mathrm{H}$ & $\mathrm{E} / \mathrm{H}$ & $\mathrm{E} / \mathrm{H}$ & $\mathrm{E} / \mathrm{H}$ \\
\hline 1. Develop a partnership with the patient & $15(75 \%) / 0$ & $4 / 0$ & $4 / 0$ & $3 / 0$ & $4 / 0$ \\
\hline $\begin{array}{l}\text { 2. Establish patient's preferences for } \\
\text { information }\end{array}$ & $8(40 \%) / 0$ & $3 / 0$ & $3 / 0$ & $1 / 0$ & $1 / 0$ \\
\hline $\begin{array}{l}\text { 3. Establish patient's preferences for role } \\
\text { in decision making }\end{array}$ & $4(20 \%) / 2(10 \%)$ & $2 / 0$ & $1 / 1$ & $1 / 1$ & $0 / 0$ \\
\hline $\begin{array}{l}\text { 4. Respond to the patient's ideas, } \\
\text { concerns \& expectations }\end{array}$ & $4(20 \%) / 2(10 \%)$ & $2 / 0$ & $1 / 1$ & $1 / 1$ & $0 / 0$ \\
\hline $\begin{array}{l}\text { 5. Identify choices \& evaluate the } \\
\text { evidence }\end{array}$ & $2(10 \%) / 4(20 \%)$ & $0 / 2$ & $0 / 1$ & $2 / 1$ & $0 / 0$ \\
\hline 6. Present evidence & $2(10 \%) / 6(30 \%)$ & $0 / 1$ & $0 / 2$ & $2 / 0$ & $0 / 3$ \\
\hline 7. Negotiate a decision & $3(15 \%) / 4(20 \%)$ & $1 / 0$ & $1 / 1$ & $1 / 2$ & $0 / 1$ \\
\hline 8. Agree on an action plan and follow-up & $2(10 \%) / 7(35 \%)$ & $1 / 2$ & $1 / 3$ & $0 / 2$ & $0 / 0$ \\
\hline
\end{tabular}

With respect to pharmacist-patient encounters most conducive to the practice ISDM, both community pharmacist categories cited that encounters requiring over-the-counter and alternative medications, those involving newly diagnosed patients and those involving patients with chronic diseases such as hypertension, asthma, and diabetes, as being most favorable to ISDM. Both hospital pharmacist categories identified situations involving management of chronic conditions or provision of palliative care programs as being most favorable to practice ISDM. Examples cited by hospital pharmacists included management of deep vein thrombosis through warfarin therapy, renal disease, cancer, HIV/AIDS, hypertension, diabetes, and hyperemesis.

When asked about their perspectives on incorporating the ISDM competencies into the pharmaceutical care model, there was considerable difference among the pharmacists' responses. Most hospital pharmacists believed ISDM should be incorporated into the pharmaceutical care model, while the community pharmacists were split between incorporating ISDM into pharmaceutical care and incorporating pharmaceutical care into ISDM; the latter group believed that ISDM was larger than pharmaceutical care. Despite the difference in opinions, all pharmacists interviewed felt it would be beneficial to have a consistent approach to patient-pharmacist collaboration among the different health disciplines, and suggested that the ISDM framework could serve as that model.

\section{DISCUSSION}

While all participating pharmacists in this study suggested that the ISDM competencies were relevant to the practice of pharmacy and the model could serve as a framework for teaching pharmacy students how to develop and sustain therapeutic relationships with patients; not all competencies were considered to be most important by the pharmacists and certain competencies were considered to be more challenging than others to implement within their respective practice settings. This discrepancy suggested an important gap between what is considered to be a desirable practice as defined by the profession of pharmacy and what the reality is; an aspect that is essential for pharmacy schools to understand and also address within the curriculum.

Pharmacists from all four categories indicated that competency \#1 (Develop a partnership with the patient) was both highly relevant and most important for pharmacy practice. They all viewed building partnerships with their patients as easy, and some of the reasons given included: "seeing patients frequently enough to allow sufficient time for establishing a rapport with them", "being less intimidating to patients than physicians", and "being regarded as the most trusted professionals in society". However, most pharmacists felt that it was not sufficient to only include patients within such partnerships, and that this competency needed to also include physicians. As one community pharmacist from the dispensing group articulated 
"when you're talking about informed shared decision making, you're talking about giving the patient a well-rounded view of the whole situation, so you want to have all health care professionals interacting"; an opinion that was echoed by pharmacists in other groups.

\begin{tabular}{|c|c|c|c|c|}
\hline \multirow{2}{*}{$\begin{array}{l}\text { Barriers } \\
\text { (Themes) }\end{array}$} & \multicolumn{4}{|c|}{ Pharmacy Setting } \\
\hline & $\begin{array}{l}\text { Community } \\
\text { (Dispensing) }\end{array}$ & $\begin{array}{c}\text { Community } \\
\text { (Disease Mngt.) }\end{array}$ & Hospital (BScPharm) & Hospital (PharmD) \\
\hline $\begin{array}{l}\text { Work } \\
\text { Environment } \\
\text { Related }\end{array}$ & $\begin{array}{ll}\text { - } & \text { Time } \\
\text { - } & \text { Lack of } \\
\text { remuneration } \\
\text { - } \text { Physical } \\
\text { environment } \\
\text { - Workload/ } \\
\text { pharmacist } \\
\text { shortage/limited } \\
\text { role of technician }\end{array}$ & $\begin{array}{l}\text { - Time } \\
\text { - Lack of remuneration } \\
\text { - Employer policies } \\
\text { - Workload/ pharmacist } \\
\text { shortage/ limited role of } \\
\text { technician) }\end{array}$ & $\begin{array}{l}\text { - Time } \\
\text { - Lack of remuneration } \\
\text { - Management policies } \\
\text { - Workload / pharmacist } \\
\text { shortage }\end{array}$ & $\begin{array}{l}\text { - Time } \\
\text { - Lack of remuneration } \\
\text { - Dispensary } \\
\text { responsibilities }\end{array}$ \\
\hline $\begin{array}{l}\text { Pharmacist } \\
\text { Related }\end{array}$ & $\begin{array}{ll}\text { - } & \text { Knowledge } \\
\text { deficiencies } \\
\text { - } & \text { Resistance to ISDM }\end{array}$ & $\begin{array}{l}\text { - Skill deficiencies/ lack of } \\
\text { education/ lack of } \\
\text { framework for patient- } \\
\text { centered care } \\
\text { - } \text { Resistance to ISDM } \\
\text { - Lack of evidence for } \\
\text { some therapies } \\
\text { - Lack of information } \\
\text { resources to assist some } \\
\text { patients } \\
\text { - Need to demonstrate } \\
\text { value of PC }\end{array}$ & $\begin{array}{l}\text { - Skill deficiencies/ lack } \\
\text { of framework for patient- } \\
\text { centered care } \\
\text { - Resistance to ISDM }\end{array}$ & $\begin{array}{l}\text { - Knowledge/ skills } \\
\text { deficiencies } \\
\text { - Resistance to ISDM } \\
\text { - Lack of evidence for } \\
\text { some therapies }\end{array}$ \\
\hline Patient Related & $\begin{array}{l}\text { - Unwillingness to } \\
\text { participate/ } \\
\text { Indifference to } \\
\text { health } \\
\text { - Language } \\
\text { - } \text { Perception of } \\
\text { pharmacy } \\
\text { - Too much } \\
\text { information } \\
\end{array}$ & $\begin{array}{l}\text { - Unwillingness to } \\
\text { participate } \\
\text { - Perception of pharmacy } \\
\text { - Knowledge deficiency } \\
\text { - Total faith in physicians }\end{array}$ & $\begin{array}{l}\text { - Unwillingness to } \\
\text { Participate/ Indifference } \\
\text { to health } \\
\text { - Language/culture } \\
\text { - Perception of pharmacy } \\
\text { - Disabilities } \\
\text { - Education } \\
\text { - Expect paternalism }\end{array}$ & $\begin{array}{l}\text { - Indifference to health } \\
\text { - Language/culture } \\
\text { - Perception of pharmacy } \\
\text { - Personality } \\
\text { - Expect paternalism }\end{array}$ \\
\hline $\begin{array}{l}\text { Health System } \\
\text { Related }\end{array}$ & $\begin{array}{l}\text { - Lack of collaboration } \\
\text { - Professional } \\
\text { boundaries } \\
\text { - No access to patient } \\
\text { information }\end{array}$ & $\begin{array}{l}\text { - Lack of collaboration } \\
\text { - Physician resistance to } \\
\text { ISDM/ professional } \\
\text { boundaries } \\
\text { - No access to patient } \\
\text { information } \\
\text { - Perceptions of pharmacy } \\
\text { by health professionals }\end{array}$ & $\begin{array}{l}\text { - Lack of collaboration/ } \\
\text { ISDM not practiced } \\
\text { universally } \\
\text { - Professional boundaries } \\
\text { - No access to patient } \\
\text { - information }\end{array}$ & $\begin{array}{l}\text { - Lack of collaboration/ } \\
\text { ISDM not practices } \\
\text { universally } \\
\text { - Professional boundaries/ } \\
\text { no formal structure for } \\
\text { pharmacist involvement/ } \\
\text { lack of access to } \\
\text { physicians }\end{array}$ \\
\hline
\end{tabular}

While competencies \#2 (establishing preferences), \#4 (responding to patient questions and concerns), \#5 (Identify choices \& evaluate the evidence), \#6 (Present evidence) and \#7 (Negotiate a decision) were viewed as highly relevant to developing the patient-pharmacist relationship, the pharmacists did not consider them to be as important as competency \#1. One possible reason for the discrepancy between rating a competency highly relevant but not most important may be explained by the pharmacists' perception of their role within the health care team. As one disease management pharmacist put it, "the pharmacists' role is to arm patients with ammo, i.e., informing them about their options, so that they can go back to the doctor and make an informed decision". This notion was reiterated when the pharmacists advocated limiting the pharmacist's role in competencies \#2 (Establish patient's preferences for information) and \#4 (Respond to patient's ideas, concerns and expectations) to issues relating to pharmacotherapy only. Similarly, competencies \#3 (Establish patient's preferences for role in decision-making) and \#5
(Identify choices and evaluate the evidence) were found to be less relevant and not considered to be most important to pharmacy practice, because the pharmacists did not believe they had a role to play in therapy decisions; and if they were to get involved, it would be with the doctor not the patient. Thus, while the pharmacists believed many of the competencies to be relevant, they did not feel these competencies to be their professional responsibility.

There were several barriers articulated by the pharmacists to implementing ISDM. One major barrier was the perceived lack of collaboration between pharmacists and physicians. Some of the pharmacists conveyed that they were often reluctant to intervene because physicians were not receptive to their interventions. As one community Disease Management pharmacist stated, "the physician has to be open-minded and there aren't enough of those yet". The current literature does concur with this point of view, suggesting that most pharmacistphysician relationships in the community setting are not at a stage to allow seamless interdisciplinary 
collaboration. ${ }^{12}$ However, it was surprising to find such a large number of pharmacists from the Hospital B.Sc.Pharm category also express lack of teamwork as a barrier; specifically because most cited examples of successful pharmacist-physician collaborations have come from the hospital setting. ${ }^{2,12}$ It is noteworthy that this was not a concern voiced by the Hospital PharmD group, which may be a result of their increased ability to engage in collaborative work with physicians because of their advanced training.

Other barriers identified by pharmacists to practicing ISDM were similar to those previously identified for the practice of pharmaceutical care. ${ }^{2}$ For instance, time and remuneration were major barriers identified across all pharmacist categories, with the exception of the PharmDs who cited workload as a major barrier. A few pharmacists also cited patients' perceptions of pharmacists, their unwillingness to participate in ISDM and their lack of appropriate competencies to engage in ISDM as barriers. To minimizing the latter, some of the pharmacists suggested that regulatory bodies and professional associations should take on the responsibility to educate patients about the pharmacist's role in optimizing health and instruct them that it was okay to communicate their ideas, knowledge, values and preferences to health care professionals. Still, others felt that it was up to the pharmacists to identify their patients' readiness to engage in ISDM and to develop ways to instill the necessary competencies in their patients; a notion supported in the medical literature. Studies have found that, although patients are frequently passive during their encounters with physicians and tend to wait for verbal cues from their doctors before expressing themselves, when provided with basic information that can help them clarify their choices and help them understand which decisions would benefit from their input, many are willing to be involved in decision-making tasks. ${ }^{15,19,20,21}$

Interestingly enough, there were several pharmacist-specific characteristics that emerged during the interview process as potential impediments to pharmacists engaging in ISDM. One such trait was the pharmacists' failure to take the lead in providing patient-centered care. Several pharmacists, with exception of Hospital PharmD, indicated that they would only engage in certain competencies if asked by a patient; these included competencies \#4 (Respond to patient's ideas, concerns and expectations), \#5 (Identify choices and evaluate evidence), and \#6 (Present evidence). When asked about competency \#2 (Establish patient's preferences for information), pharmacists indicated that they often unilaterally decided the type and extent of information to provide, based on their past experience with a patient. In their defense, some of the pharmacists expressed not being adept at addressing patients' preferences regarding information, while others proposed that existing models of good counseling did not go as far enough to ask the patient for their preferences. Additionally, many shared the concern that most pharmacists had limited access to evidence-based knowledge at their practice sites.
When asked about best pharmacist-patient encounter to practice ISDM, each category of pharmacists revealed a unique set of situations. Counseling patients with regard to over-the-counter and alternative medications were two examples commonly cited by community pharmacists; this may be attributed to the fact that community pharmacists perceive themselves as having more impact on patients' decision involving self-care. ${ }^{23}$ Both community and hospital pharmacists suggested patient scenarios involving management of chronic diseases to be ideal for practicing ISDM. Pharmacists expressed that patients often came to them to better understand their chronic diseases, and to discuss their drug therapies if they were unsure about the physician's recommendation. The literature also supports the point of view that patients with chronic diseases may be more likely to engage in a more participatory clinical relationship. ${ }^{24,25}$

This exploratory study provided valuable insight into the pharmacists' perceptions of how relevant ISDM competencies were, which competencies would be the easiest to practice, what challenges and barriers existed that would make some of the competencies hard to practice and, finally, identifying pharmacistpatient encounters which would best lend to ISDM practice. Based on these findings, the physician ISDM teaching module was adapted for pharmacy students. The wording of the eight competencies was kept the same, as the pharmacists did not voice concerns over the interpretation of the competencies. To be fully appreciated, practiced and mastered, the module was delivered in the same fashion as that of the physician module; students were introduced to the competencies and given the opportunity to practice the competencies within the classroom setting using videos and standardized patients, followed by application of the competencies during their fieldwork experience. Frequently encountered pharmacist-patient scenarios in practice were used to develop the videos and train standardized patients; these scenarios have been described in detail in another publication. ${ }^{37}$ In addition, based on the viewpoints shared in this study; evidence supporting the benefits for involving patients in decision-making and the inherent dangers associated with practitioners assuming they know their patients well enough to judge what their preferences are and ignoring the need to verify their assumptions was also discussed during the in-class session. ${ }^{1,2,13-19,31}$

Furthermore, the insight into how the study pharmacists perceived themselves as health care practitioners helped pharmacy educators to identify other areas that needed addressing within the curriculum. For example, the disconnect between the scope of practice as suggested by the pharmaceutical care philosophy and what pharmacists consider as their responsibility needed to be addressed before progress could be made in the area of ISDM. Clearly, if pharmacists' consider identifying patients' choices regarding treatment and participating in decision making to help select the treatment as being primarily the physician's responsibility, they will be less likely to adopt an 
ISDM like framework within their practice. Similarly, it was important to consider strategies at the postsecondary institution level that could start fostering interprofessional teamwork, both in the classroom setting and at experiential sites. Lastly, it was important to incorporate the ISDM teaching modules into the preceptor training programs, to help preceptors to enhance their skills and practice, to in turn support students during their fieldwork education.

\section{Limitations}

While this study provided valuable insight, it is important to recognize some of its limitations. First, at the start of each interview, all pharmacists were asked to review the eight ISDM competency statements and to ask for clarification if any of the statements were not clear to them. Because all the pharmacists expressed that the statements were clear to them, the research team made the assumption that the competencies were interpreted appropriately. Unfortunately, this approach did not allow the research team to explicitly assess if in fact all the pharmacists had interpreted the competencies as intended; consequently, limiting the interpretation of some of the study findings. For example, when the pharmacists expressed that forming a "partnership" to be the most relevant of all competencies but rated "establishing patients' preferences for role" and "identifying choices" as not being highly relevant, knowing specifically how their interpretation of "partnership" differed from that of the ISDM model (where establishing patients' preferences for role and identifying choices are essential components of an effective partnership) could have helped understand this discrepancy. Second, the small sample size in each of the groups could be viewed by those familiar with quantitative methodologies as a limitation. However, the research team ensured data saturation had occurred with the sample size used, thus not requiring recruitment of additional pharmacists; an approach that is consistent with the concept that "theoretical saturation is akin to redundancy". ${ }^{36}$ Third, the pharmacists in this study were selectively recruited from a cohort of preceptors affiliated with UBC, whether more mainstream pharmacists would demonstrate similarly views of the ISDM competencies remains to be tested. Fourth, it may have been informative to ask the pharmacists to describe elements of ISDM that they currently use in their practice, as this may have helped shed light onto how this model was currently being used in practice, and possibly provide an appreciation of the "theory-practice" gap. Finally, it is possible that the pharmacists may not have been able to truly assess the relevance, importance, difficulty and ease of the ISDM competencies, if they have not had the opportunity to practice and experience these competencies with their patients. Thus, it may be worthwhile to repeat the interview process after the pharmacists have had the opportunity to participate in the preceptor ISDM training program and practice the competencies with patients at their site.

\section{CONCLUSIONS}

With the advent of patient-centered care and a growing movement towards increased patient participation in their health, health care practitioners must learn to establish relationships with their patients. Central to this philosophy in pharmacy is the therapeutic relationship model, which emphasizes patient participation and open communication between pharmacists (practitioners) and patients. Based on the assessment given by the pharmacists interviewed in this study, the physician derived ISDM competencies can provide pharmacy students with a framework to effectively engage in therapeutic relationships. Subsequent to this study, the project leader secured funding from the American Association of Colleges of Pharmacists and the American Foundation to develop an educational workshop to assist pharmacy students and practicing pharmacists to hone skills related to ISDM.

\section{ACKNOWLEDGEMENT}

Dr. William Godolphin and Dr. Angela Towle from the Division of Health Care Communication in the College of Health Disciplines, University of British Columbia for their leadership; all the pharmacists who participated in the focus group; and Mr. Maxwell Murray for his hard work as research student for this project. We would also like to thank the College of Pharmacists of British Columbia and the British Columbia Pharmacy Association for funding of this project.

\section{CONFLICT OF INTEREST}

No conflicts of interest exist for any of the authors. This project was funded by the College of Pharmacists of British Columbia and the British Columbia Pharmacy Association.

The views and opinions expressed in this paper are her own and not those of her employer, $A B C$ Benefits Corporation (Alberta Blue Cross). Alberta Blue Cross neither endorses nor supports the author's views and opinions.

\section{References}

1. Economist: Tomorrow's doctoring, patient heal thyself 1995 (February 4th):19-21.

2. Cipolle RJ, Strand LM, Morley, PC. A New Professional Practice. In: Pharmaceutical Care Practice, 1st ed. McGraw Hill, New York, NY; 1998. pp 1-35.

3. Strand LM, Cipolle RJ, Morley PC. Pharmaceutical Care: An Introduction. In: Current Concepts, Upjohn Company, Kalamazoo, Ml 1992.

4. Hepler CD, Strand LM. Opportunities and Responsibilities in Pharmaceutical Care. Am J Pharm Educ 1989;53:7S-15S. 
5. Berger BA. Building an effective therapeutic alliance: Competence, trustworthiness, and caring. Am J Hosp Pharm 1993;50:2399-2403.

6. Herrier RN, Boyce RW. Establishing an Active Patient Partnership. Am Pharm 1995;NS35(4): 48-57.

7. McDonough RP. Interventions to Improve Patient Pharmaceutical Care Outcomes. J Am Pharm Assoc 1996;NS36(7):453-465.

8. Winslade NE, Strand LM, Pugsley JA, Perrier DG. Practice Functions Necessary for the Delivery of Pharmaceutical Care. Pharmacotherapy 1996;16:790-898.

9. Sleath B. Pharmacist-patient relationships: authoritarian, participatory, or default? Patient Educ Couns 1995;28: 253-63.

10. Graber DR, Bellack JP, Lancaster C, Musham C. Curriculum Topics in Pharmacy Education: Current and Ideal Emphasis. Am J Pharm Educ 1999;63:145- 151.

11. Towle A, Godolphin W. Framework for teaching and learning informed shared decision making. BMJ 1999;319:766-71.

12. McDonough RP, Doucette WR. Developing collaborative working relationships between pharmacists and physicians. J Am Pharm Assoc 2001;41(5):682-692.

13. Greenfield S, Kaplan S, Ware, J. Expanding patient involvement in care: effect on patient outcomes. Ann Intern Med 1985;102:520-528.

14. Gordon D. MD's failure to use plain language can lead to the courtroom. Can Med Assoc J 1996;155:1152-3.

15. Flood AB, Wennberg JE, Nease Jr RF, Fowler Jr FJ, Ding J, Hynes LM. The importance of patient preference in the decision to screen for prostate cancer. J Gen Intern Med 1996;11: 342-349.

16. Stewart MA. Effective physician-patient communication and health outcomes: a review. Can Med Assoc J 1995;152 (9):1423-1433

17. Garrett DG, Martin LA. The Ashville Project: participants' perceptions of the factors contributing to the success of a patient self-management diabetes program. J Am Pharm Assoc 2003;43:85-90.

18. Cranor CW, Bunting, BA, Christensen, DB. The Asheville Project: longterm clinical and economic outcomes in a community pharmacy diabetes care program. J Am Pharm Assoc 2003;43:185-190.

19. Chewning B, Sleath B. Medication Decision-Making and Management: A Client-Centered Model. Soc Sci Med 1996;42:389-398.

20. Kasper JF, Mulley Jr AG, Wennberg JE. Developing shared decision making programs to improve the quality of health care. QRB 1992;18(6),183-190

21. Barry MJ, Fowler Jr FJ, Mulley Jr AG, Henderson Jr JV, Wennberg JE. Patient reactions to a program designed to facilitate patient participation in treatment decisions for begnin prostatic hyperplasia. Med Care 1995;33(8):771-782.

22. Britten N, Stevenson FA, Barry CA, Barber N, Bradley CP. Misunderstanding in prescribing decisions in general practice: qualitative study. BMJ 2000;320, 484-488.

23. Kassam R, Farris, KB, Burback L, Volume Cl, Cox CE, Cave A. Pharmaceutical care research and education project (PREP): pharmacists' interventions. J Am Phar Assoc 2001;41:401-410.

24. Kassam R, Vaillancourt R, Trottier M, Gervais A. Evaluation of pharmacist-managed nonprescription drug benefit for Canadian military personnel. J Am Pharm Assoc 2005;45:170-178.

25. Gotler RS, Flocke SA, Goodwin MA, Zyzanski SJ, Murray TH, Stange KC. Facilitating Participatory Decision-Making What happens in real-world community practice? Med Care 2000;38:1200-1209.

26. Garett DG, Bluml BM. Patient self-management program for diabetes: first-year clinical, humanistic, and economic outcomes. J Am Pharm Assoc 2005; 45:130-7.

27. Romanov RJ. (2002). Commission on the future of health care in Canada. Building on values. The future of health care in Canada. Final report. Available at: www.hc-sc.gc.ca/english/pdf/romanow/pdfs/HCC_Final_Report.pdf (accessed Oct 13, 2007).

28. National Association of Pharmacy Regulatory Authorities (NAPRA). Model Standards of Pharmacy for Canadian Pharmacists. April 2003. Available at: www.napra.org/docs/0/95/123.asp (accessed Oct 13, 2007).

29. BC College of Pharmacy. Framework of Professional Practice. April 2003. Available at: www.bcpharmacists.org/Portals/0/PDF/Standards/FPP.pdf (accessed Oct 13, 2007).

30. Allen LV, Popovich NG, Ansel HC. In: Ansel's Pharmaceutical Dosage Forms and Drug Delivery Systems, 8th ed. Lippincott Williams \& Wilkins, New York, NY; 2005. pp 20-21. Available at: http://books.google.com/books? $\mathrm{id}=x 1 \mathrm{H} 7 \mathrm{Tn} 2 \mathrm{qig} 4 \mathrm{C} \& \mathrm{pg}=\mathrm{PA} 21 \& \mathrm{lpg}=\mathrm{PA} 21 \& \mathrm{dq}=30+$ american+pharmaceutical+association +principles+of+practice+for+pharmaceutical+care\&source=web\&ots=EQ9leQXiA_\&sig=Cq6jNFRTuek62zsaG7z6z8LJN 3І\#PPA22,M1 (accessed Oct 13, 2007).

31. Province of British Columbia, Ministry of Health. New Directions for a Healthy British Columbia; British Columbia, Canada; 1993. pp 7 \& 13

32. Association of Faculties of Pharmacy of Canada (AFPC). (2004) AFPC educational outcomes for a baccalaureate pharmacy education in Canada, Canada 1998. Available at: http//.www.afpc.info/content.php?sectionID=2\&Language=en (accessed Oct 13, 2007).

33. Canadian Council for Accreditation of pharmacy programs. Competencies for Canadian pharmacists. Available at: http://www.ccapp-accredit.ca/standards/ (accessed Oct 13, 2007).

34. Kassam R. Focus Group Methodology to Develop a Community Pharmaceutical Care Clerkship Program. Am J Pharm Educ 2003;67:Article 88.

35. Weston WW. Informed and shared decision-making: the crux of patient-centered care. Can Med Assoc J 2001; 165:438439.

36. Strauss A, Corbin J. Basics of Qualitative Research: grounded theory procedures and techniques. Newbury Park, CA: Sage Publications; 1990 
Kassam R, Volume-Smith C, Albon SP. Informed shared decision making: An exploratory study in pharmacy. Pharmacy Practice 2008 Apr-Jun;6(2):57-67.

37. Kassam R, Albon S, Bainbridge L, Suto M, Collins, J. Learning by doing: enhancing interprofessional students' awareness of Informed Shared Decision Making. Internet Journal for Allied Health Sciences and Practice 2006; 4(4)- . Available at: http://ijahsp.nova.edu/articles/vol4num4/kassam.htm 